\title{
Spatial heterogeneity of the bioluminescence field of the tropical Atlantic Ocean and its relationship with internal waves
}

\author{
V. M. Kushnir ${ }^{1}$, Yu. N. Tokarev ${ }^{2}$, R. Williams ${ }^{3, *}$, S. A. Piontkovski ${ }^{2}$, P. V. Evstigneev ${ }^{2}$ \\ ${ }^{1}$ Marine Hydrophysical Institute, 2 Kapitanskaya st., 335000 Sevastopol, Ukraine \\ ${ }^{2}$ Institute of Biology of the Southern Seas, 2 Nakhimov av., 335011 Sevastopol, Ukraine \\ ${ }^{3}$ Plymouth Marine Laboratory, Prospect Place, Plymouth PL1 3DH, United Kingdom
}

\begin{abstract}
Field research was conducted during a number of cruises (1982-1986) to the western part of the tropical Atlantic Ocean. A survey taken in summer of 1985 was selected for detailed evaluation because it consisted of: (1) transects, based on continuous bioluminescence records made when the vessel was underway, (2) drift stations with simultaneous measurements of bioluminescence $(110 \mathrm{~m}$ depth), temperature, salinity, density and current profiles (1000 $\mathrm{m}$ depth) and (3) 4 buoy stations with current and temperature autonomous recorders. Spectra of bioluminescence fluctuations obtained from continuous records have a number of peaks, most of which developed at 12 to 13,8 and $5 \mathrm{~km}$ wavelengths, and, in the vertical bioluminescence structure, heterogeneities ranging in size from 10 to $50 \mathrm{~m}$ were registered. These horizontal and vertical scales correspond to the scales of the near-inertial gravity waves, which were observed in data from the buoy stations, and vertical current and density profiling. The waves behave as quasi-stationary fluctuations, generating the conditions for aggregation of the bioluminescent organisms along the horizontal and in the vertical planes. The concept that the origin of fluctuations in bioluminescence is to be found in near-inertial gravity waves also explains the latitudinal effect of the changes in variance of the size and dispersion of bioluminescence heterogeneities averaged latitudinally over $5^{\circ}$ intervals over the Tropical and Subtropical Atlantic Ocean.
\end{abstract}

KEY WORDS: Bioluminescence Plankton - Near-inertial gravity waves - Spatial heterogeneity Atlantic Ocean

\section{INTRODUCTION}

Spatial-temporal heterogeneity of plankton communities is affected by a number of general features of marine ecosystems. A large amount of research has been devoted to gaining an understanding of this phenomenon and the interrelation between the structure of plankton communities and various hydrophysical processes (Vinogradov et al. 1971, Piontkovski \& Goldberg 1984, Mann \& Lazier 1991). Plankton communities, in the range of the synoptic scales of variability, are influenced mainly by vertical currents which also influence the distribution of nutrients and oxygen in

·Addressee for correspondence.E-mail: bw@wpo.nerc.ac.uk the upper euphotic zone of sea. They are also impacted by intensive eddy systems which can transfer near coastal waters and their biota into oceanic waters (Wiebe et al. 1976, Owen 1981, Bradford et al. 1982, Angel \& Fasham 1983, Falkowski et al. 1991, Piontkovski et al. 1995, 1997).

Considerably fewer data are avallable concerning the relationship of plankton communities with smaller scale hydrophysical processes and in particular with internal waves. These waves are ubiquitous in the World Ocean and strongly influence chemical and optical characteristics of the water as well as processes of vertical exchange. Conventional methods of measurements of biological variables from stations located over 20 to $30 \mathrm{~km}$ apart and in a limited numbers of depth horizons, from tens to hundreds of meters, are 
practically unacceptable for research into this problem because of non-correspondence of the scales of such data with internal waves. Therefore, biophysical methods and, in particular, horizontal and vertical profiling of the bioluminescence characteristics of the plankton can be very effective in research on the small-scale spatial and temporal structure of plankton communities. A large amount of work was carried out in the former Soviet Union on bioluminescence as an indicator of the 'health' of the biota. Continuous bioluminescence is only observed in bacteria while in phyto- and zooplankton it occurs as flashes and can be activated by a variety of stimuli such as mechanical, electrical, chemical stimuli or by light. About $80 \%$ of the energy is radiated in wavelengths between 450 and $550 \mathrm{~nm}$ with a maximum at 470 to $490 \mathrm{~nm}$, which is the bluegreen region of the spectrum where transparency of marine water is at a maximum.

The bioluminescence intensity in the World Ocean mirrors biological productivity and because of this can serve as a biological indicator to monitor the structure and variability of marine ecosystems over a wide range of spatial-temporal scales and geographical regions (Bitukov 1982, Marra \& Hartwig 1984, Marra 1989, Evstigneev \& Bitukov 1990, Gitelson et al. 1992 Buskey 1993). The bioluminescent flashes generated by organisms can be characterised by a number of parameters: the spectral band, the frequency and duration of flashes, the amplitude of the spectrum and the bioluminescence potential or intensity. The lastmentioned parameter enables different ocean regions to be compared on the basis of the integrated characteristics. The bioluminescence potential is the maximal amount of radiant energy to be emitted by stimulated bioluminescent organisms in a given volume of water The bioluminescence potential $\left(B_{p}\right)$ can be estimated as:

$$
B_{p}=\int_{0}^{t} B(t) \mathrm{d} t
$$

where $B(t)$ is the light intensity during the bioluminescent flash $t$.

$B_{p}$ values are equivalent to the irradiation on the illuminator of the input photometer and change in a wide range, from 0.01 to $15-20 \times 10^{-2} \mu \mathrm{W} \mathrm{cm} \mathrm{cm}^{-2}$, in the ocean This parameter is spatially heterogeneous throughout a number of spatial-temporal scales (Vladimirov et al. 1972, Gitelson \& Filimonov 1980, Evstigneev et al. 1994). Such heterogeneity is the consequence of the aggregation behaviour of planktonic animals generating flashes (copepods, euphausiids, ostracods, dinoflagellates, etc.). Spatial distribution and aggregation of the above groups of organisms are determined by internal biological mechanisms regulating the population dynamics as well as hydrophysical processes (Vinogradov et al. 1971, Marra \& Hartwig 1984, Her- ring 1993, Lapota et al. 1994, Piontkovski \& Williams 1995. Piontkovski et al. 1997). Such a diversity of factors affecting the distribution of plankton cause difficulties when spatial distribution or biological productivity have to be interpreted on the basis of oceanographic data. One aspect of this problem, the relationship between 2-dimensional variability of spatial bioluminescence and that of internal gravity waves, is considered.

\section{METHODS}

Data were obtained from a number of expeditions of the RV 'Academic Vernadsky' (Ukrainian Academy of Sciences) to the western tropical Atlantic Ocean (1982-1986). A grid survey, taken from 'Vernadsky', Voyage 32, 27 June until 17 August 1985, which had the majority of bioluminescence casts centred around $7^{\circ} \mathrm{N}, 42^{\circ} \mathrm{W}$, was selected (Fig. 1). The region of the survey was in the southwestern part of the Northern Tropical Convergent Zone, which is formed by the waters of the southern branch of the North Passat Current. These waters are characterised by an increased salinity of approximately $37 \%$ in the surface layer with a high transparency of water and an attentuation coefficient, $\varepsilon=0.06$ to $0.1 \mathrm{~m}^{-1}$, in the blue-green part of spectrum $(490 \mathrm{~nm})$. Transparency of water decreases with depth, and maximum attenuation coincides with the depth of the pycnocline where $\varepsilon$ changes from 0.08 to $0.2 \mathrm{~m}^{-1}$ (Shifrin 1978. Bulgakov et al. 1991, Mankovsky 1996).

The survey consisted of: (1) transects based on continuous bioluminescence records taken when the vessel was underway and (2) drift stations with bioluminescence profile measurements to $110 \mathrm{~m}$ depth (thickness of the photic layer) and, temperature, salinity, density and current profiles to $1000 \mathrm{~m}$ depth (thickness of the baracline layer). Measurements of bioluminescence ( 34 horizontal tows and 143 vertical casts) were conducted within a period from $2 \mathrm{~h}$ after sunset to $2 \mathrm{~h}$ before sunrise to exclude the impact of the vertical migrations of the plankton and the diel light rhythm.

The bioluminescence intensity was measured by means of a bathyphotometer with a dynamic band (db) of 57. The sensitivity of the bioluminescence sensor was in a range from $10^{-7}$ to $10^{-2} \mu \mathrm{W} \mathrm{cm} \mathrm{cm}^{-2}$ with a band of spectral sensitivity from 160 to $600 \mathrm{~nm}$. The repeat time of the bioluminescence, temperature and conductivity sensors was $180 \mathrm{~ms}$. The bathyphotometer was deployed at a speed of 1.1 to $1.3 \mathrm{~m} \mathrm{~s}^{-1}$. The bioluminescence of planktonic organisms have a total latent period and flash duration less than $0.6 \mathrm{~s}$, which means that the sensor can easily measure the bioluminescence signal. Signals from the submersible gear were 
Fig. 1 Cruise track and station positions of Voyage 32 of the 'Academic Vernadsky' from 27 June to 17 August 1985. Black dots indicate positions of the 4 buoy stations

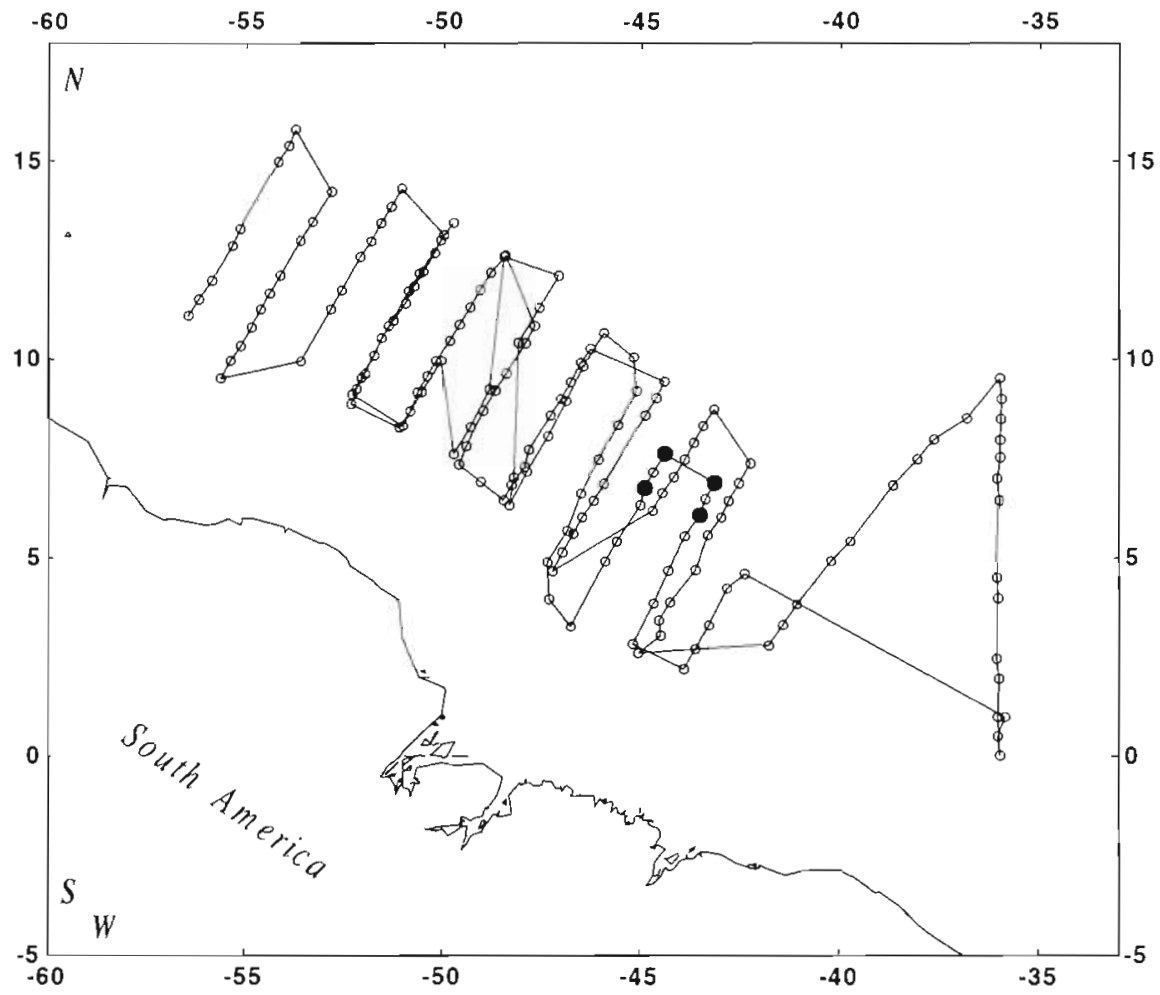

transferred up the cable to the onboard unit. To protect the bioluminescence sensor from downwelling light and to ensure comparability of mechanical stimulation of the organisms a special 'dark' enclosure was mounted on the end of the tube housing the photomultipliers. The conductivity/temperature/depth profiler (CTD) and the bioluminescence sensor were mounted together in the same instrument package. The bioluminescence signals coming from the submersible unit were recorded and averaged over $5 \mathrm{~s}$ intervals. To calibrate the sensor a radioactive luminescent light source was used. The light intensity of this standard source was $1.2 \times 10^{-2} \mu \mathrm{W}$. A measure of the background light was taken as the minimal bioluminescence signal from $1 \mathrm{~m}$ depth. The depth of the submersible gear was estimated by means of the pressure sensor DDV (precision $0.01 \mathrm{MPa}$ ). The absolute errors of the other sensors were $0.01^{\circ} \mathrm{C}$ for temperature

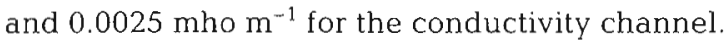

During the recording of horizontal transects the bioluminescence instrument package was placed in a sealed container and mounted on the bottom of the vessel. The integration time of the bioluminescent sensor was manually regulated in a band from 0.5 to $30 \mathrm{~s}$ (Vladimirov et al. 1972). The spatial-temporal averaging of the single flashes is the key in the assessment of the spatial field of bioluminescence heterogeneities. It is necessary to take the following factors into account: the attenuation of light due to scattering and absorp- tion processes, and the angular sensitivity of the sensor receiving the bioluminescence signals in water. In addition to these effects, it is necessary to take into account the separate temporal averaging of the bioluminescence signals by the integrating circuits of the instrument with a constant time equal to $T$.

The ratio for the relationship of the bioluminescence field spectrum $S_{B}(\omega)$ and the output signal $S(\omega)$ can be represented as:

$$
S(\omega)=V_{0}^{-1} S_{B}\left(\omega / V_{0}\right)\left|G\left(\omega / V_{0}\right)\right|^{2}\left(1+\omega^{2} T^{2}\right)^{-1}
$$

where $V_{0}$ is the speed of the sensor movement, $\omega=2 \pi f$ is the angular frequency, and $\left|G\left(\omega / V_{0}\right)\right|^{2}$ is the square of the module of the amplitude-frequency characteristics of the bioluminescence sensor, which has the following definition for a round form of photometric sensor (Urdenko 1977):

$\left|G\left(\omega / V_{0}\right)\right|^{2}=$

$4 p^{2}\left(\sin \theta_{0}\right)^{-4}\left[0.25 p^{2} \ln ^{2}\left(1+p^{-2}\right)+\left(p \cdot \operatorname{arcg} p^{-1}-1\right)^{2}\right]$

where $p=\varepsilon V_{0} / \omega$ and $\theta_{0}$ is the angle of vision of the bioluminescent sensor.

From Eq. (3) it is obvious that the spectral characteristics of the bioluminescence sensor depends upon the transparency of the sea water. In pristine waters, when spatial averaging covers large volumes, smallsize heterogeneities are less detectable than in turbid waters, where the averaging requires smaller volumes. For instance, when $\varepsilon=0.1 \mathrm{~m}^{-1}$, the transparency band 
corresponds to the wave $0.1 \mathrm{rad} \mathrm{m} \mathrm{m}^{-1}$; when $\varepsilon=1.0 \mathrm{~m}^{-1}$, the transparency band expands to $1.0 \mathrm{rad} \mathrm{m}^{-1}$ Therefore, it is expedient to use the minimum possible significances $\varepsilon$ for the determination of detectable dimensions of the bioluminescence heterogeneities.

When $p \ll 1$,

$\left|G\left(\omega / V_{0}\right)\right|^{2}=4 p^{2}\left(\sin \theta_{0}\right)^{-4}\left[p^{2} \operatorname{In}^{2} p+(0.5 \pi p-1)^{2}\right]$

and at reduced $p$ the spectral characteristics of the sensor moves to zero.

When $p \gg 1$ (turbid waters),

$$
\left|G\left(\omega / V_{0}\right)\right|^{2}=1 /\left(\sin ^{4} \theta_{0}\right)
$$

i.e. the sensitivity to heterogeneities of that size depends upon the angle of vision of the sensor and sharply decreases when the angle decreases. A theoretical increase to infinity of $\left|G\left(\omega / V_{0}\right)\right|^{2}$ with the decrease of the angle of vision does not take place due to diminishing sensitivity of the sensor.

The spectral properties of the bioluminescence sensor also depends upon the frequency characteristics of its inertia time (constant time $T$ ). The optimal condition for concordance between the spatial and temporal averaging of the bioluminescence heterogeneities takes place when the components of the signal that have not been depressed by the spatial averaging in the parcel of scanned water are filtered. The boundary frequency is equal to $\omega_{0}=2 \pi / T$ and it corresponds to the wave number $k_{0}=2 \pi / V_{0} T$. From Eq. (3) it can be established that when measurements are taken in transparent waters $\left(\varepsilon<0.1 \mathrm{~m}^{-1}\right)$ the transparency band of the bioluminescence sensor is $k_{0}=0.05 \mathrm{rad}$ $\mathrm{m}^{-1}$. This corresponds to $T=2 \pi / k_{0} V_{0}=25.12 \mathrm{~s}$ at a sensor speed of $5 \mathrm{~m} \mathrm{~s}^{-1}$. The value $V_{0} \approx 1.2 \mathrm{~m} \mathrm{~s}^{-1}, T=$ $1.3 \mathrm{~s}$, for the vertical profiling mode, but the band of a signal is restricted by the wave numbers 0.3 to $0.1 \mathrm{rad}$ $\mathrm{m}^{-1}$ in this case. Spatial heterogeneities corresponding to this scale of wave numbers are at the limit of the detectable values and might be assessed by sensors with a more narrow angle of vision. For measurements with the bathyphotometer in tropical Atlantic Ocean regions the following estimates have been used.

(1) For horizontal measurement, $\varepsilon=0.06 \mathrm{~m}^{-1}, k_{0}=$ $0.05 \mathrm{rad} \mathrm{m^{-1 }}, V_{0}=7 \mathrm{~m} \mathrm{~s} \mathrm{~s}^{-1}, T=17.94 \mathrm{~s}$. The minimal detectable dimensions of bioluminescence heterogeneities were equal to $125.6 \mathrm{~m}$.

(2) For vertical profiling, $\varepsilon=0.08 \mathrm{~m}^{-1}, V_{0}=1.2 \mathrm{~m} \mathrm{~s}^{-1}$, $T=2 \mathrm{~s}, \theta_{0}=24^{\circ}$, and $k_{0}=2.41 \mathrm{rad} \mathrm{m}{ }^{-1}$. The minimal detectable vertical dimension of bioluminescence heterogeneities was about $2 \mathrm{~m}$.

Besides measurements taken on board, continuous records of temperature and the current speeds from 4 buoy stations (Fig. 1) from the same cruise were used in our calculations of the characteristics of the internal waves. Every hour wind velocity, its direction, humidity, atmospheric pressure and intensity of solar radiation were measured.

The CTD 'Istok' (with a temperature sensitivity of $0.0025^{\circ} \mathrm{C}$, a measurement error of not more than $0.01^{\circ} \mathrm{C}$, and a sensor response time of about $50 \mathrm{~ms}$ ) was used for vertical profiling. The electrical conductivity was measured within the limits of 1.3 to $7 \mathrm{mho} \mathrm{m}^{-1}$; the sensitivity was $0.0025 \mathrm{mho} \mathrm{m}^{-1}$ with a measurement error not more $0.002 x$, where $x$ is the conductivity. The hydrostatic pressure was estimated by means of a pressure sensor which had a band of 0 to $60 \mathrm{MPa}(0$ to $6000 \mathrm{dbar}$, a sensitivity 0.004 to $0.007 \mathrm{MPa}$ and a measurement error not more $0.05 \mathrm{MPa}$.

For measurement of the vertical structure of currents a 3-component acoustic profiler was used. The main characteristics of the measurements of the current speed were: a range from -3 to $3 \mathrm{~m} \mathrm{~s}^{-1}$, sensitivity of $4 \mathrm{~mm} \mathrm{~s}^{-1}$, an error of not more than $(1+4 \mathrm{~V}) \times 10^{-2} \mathrm{~m} \mathrm{~s}^{-1}$, where $V$ is the measured velocity of a current

In addition to single casts, long-term records of temperature, and of the direction and velocity of the currents were made at the buoy stations by means of the self-contained current meter 'Disk'. The impeller sensors were mounted to measure currents within a range from 0 to $1.8 \mathrm{~m} \mathrm{~s}^{-1}$, with a sensitivity of $7 \mathrm{~mm} \mathrm{~s}^{-1}$. The sensor package was set for a sampling time interval of 5 min and in this mode measurements could be taken for 900 h. Data were stored within the submersible modules. A detailed description of the abovementioned hydrographic equipment can be found in Bulgakov et al. (1991).

At the 4 buoy stations, current and temperature recorders were distributed vertically at 25,50,75, 100, $150,200,300,500,750,1000$, and $1500 \mathrm{~m}$. The distances between the buoy stations ranged from 17 to $38 \mathrm{~km}$. Measurements were taken from each depth horizon for $17 \mathrm{~d}$ with a temporal resolution of $5 \mathrm{~min}$.

Various methods of spectral analysis were used to determine the period and phase characteristics of the main fluctuations of current and temperature, and to define the main space scales of bioluminescence heterogeneity in the horizontal transects

\section{RESULTS AND DISCUSSION}

\section{The macroscale dynamics of waters}

The macroscale circulation in the western tropical Atlantic Ocean is under the control and interaction of 3 major gyres; the North Subtropical Anticyclonic Gyre, the North Tropical Cyclonic Gyre and the Equatorial Anticyclonic Gyre. The last one predetermines the patterns and positions of the main currents. In a system of 
currents the North Equatorial Countercurrent (NECC) acts as the main circulation element originating from the Guyana Current, bifurcating and turning to the east. The precise position of these 2 limbs varies over seasons. The second source of the NECC is the North Equatorial Current (NEC), which feeds from the north. The NECC is usually contained in the upper 100 to $200 \mathrm{~m}$ layer and has a width about $700 \mathrm{~km}$ with a double-core structure. The NECC has a well-pronounced easterly transport in June-July of 30 to 40 sverdrup (Sv), with the largest geostrophic velocity being 100 $\mathrm{cm} \mathrm{s}^{-1}$. The structure of the temperature and salinity fields in the zones of tropical divergence and convergence bordering the northern and southern boundaries of the NECC is well developed. In the Northern Tropical Divergence $\left(8^{\circ} \mathrm{N}\right.$ approximately) the depth of maximum salinity was from 50 to $70 \mathrm{~m}$ with the thermocline displaced to the mixed layer (10 to $20 \mathrm{~m}$ ). The Northern Tropical Convergence has a large mixed layer, which can extend down to a depth of $150 \mathrm{~m}$

\section{Horizontal and vertical components of the bioluminescence field}

A typical section from the continuous horizontal records of the towed bathyphotometer is represented in Fig. 2. Obvious patterns in the increase and decrease of $B_{p}=f(x)$ values on a scale from 1 to $10 \mathrm{~km}$ can be noted. Spectral data analyses revealed the precise wave numbers $(k)_{i} k=2 \pi / \lambda$. The length of 1 tow was usually 100 to $160 \mathrm{~km}$, which ensured degrees of freedom from 20 to 30 for heterogeneities $10 \mathrm{~km}$ in size. It can be demonstrated from the spectrum of the wave number of the bioluminescence potential of the horizontal heterogeneities, $S_{B p}(k)$, that the main spectral peak corresponds to horizontal heterogeneities 12 to

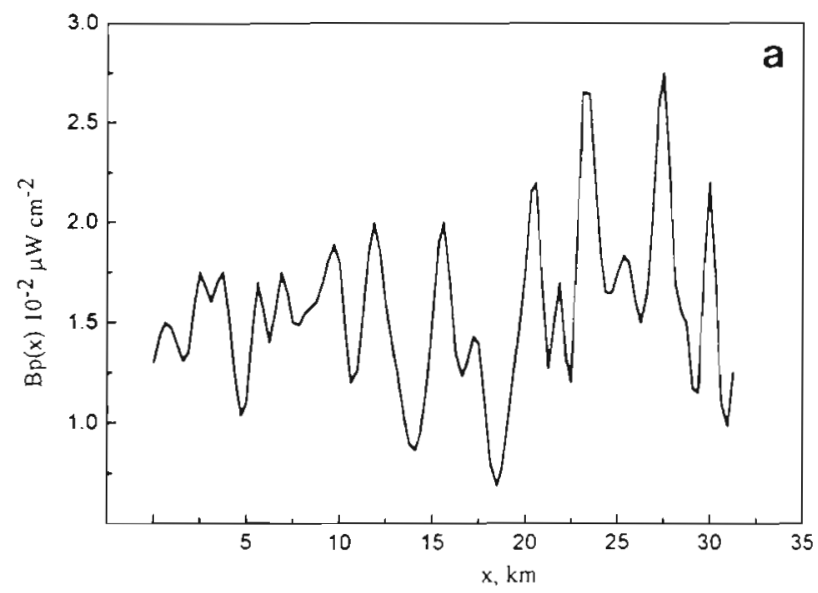

Fig. 2. (a) Horizontal ( $x$ ) and (b) vertical ( $z$ ) profiles of bioluminescence in studied region. $B_{p}$ : bioluminescence

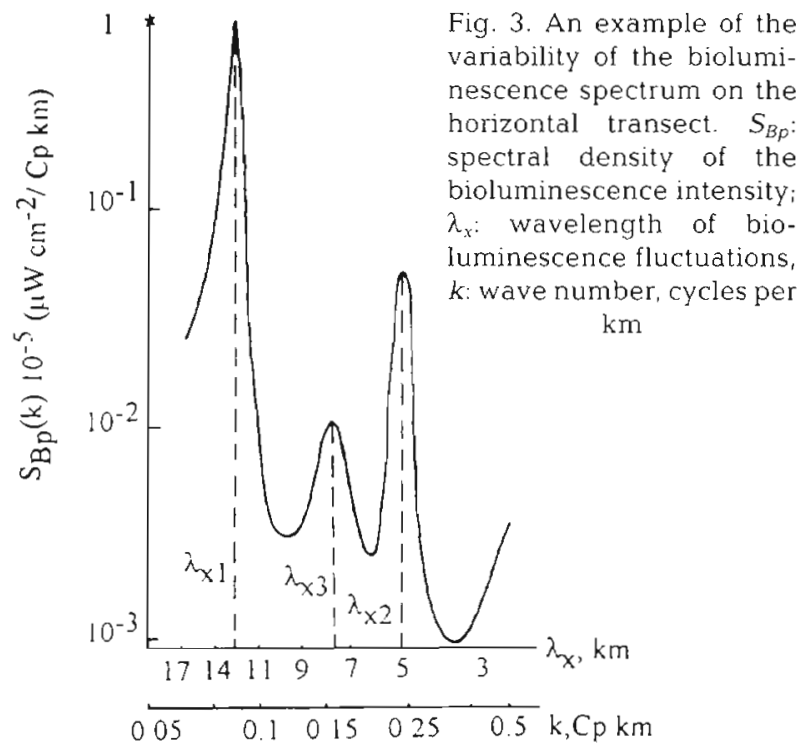

$13 \mathrm{~km}$ in size (Fig. 3). The second peak (ranked by amplitude) corresponds to approximately $5 \mathrm{~km}$ and the third to approximately $8 \mathrm{~km}$. Heterogeneities of 18 to $20 \mathrm{~km}$ and 2.5 to $4 \mathrm{~km}$ were noted for a number of tows and considered as the marginal assessments of the studied spatial range. The bioluminescence vertical profiles $B_{p}(Z)$, show a sharply layered structure of the bioluminescence field (Fig. 2b), where heterogeneities were from 10 to $40-50 \mathrm{~m}$ in the vertical axis. The sharp $B_{p}(z)$ maxima at depths of $20 \mathrm{~m}$ were perhaps associated with the vertical water density gradient, which was well developed in CTD measurements.

In general, horizontal and vertical measurements of bioluminescence potential show that the bioluminescence field is characterised by heterogeneities from $3-5$ to $15-20 \mathrm{~km}$ along the horizontal axis and from 10 to $50 \mathrm{~m}$ along its vertical axis. To identify the mecha-

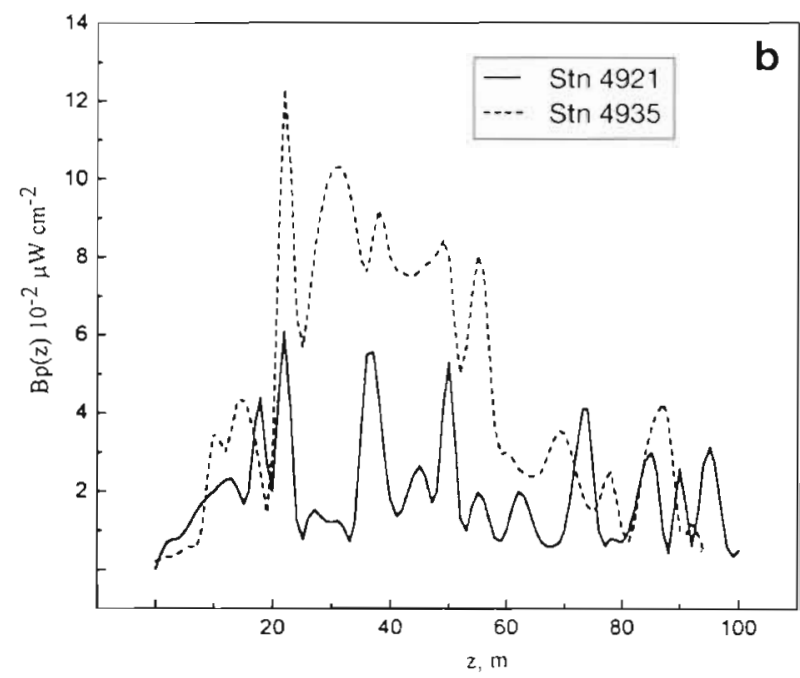


nisms governing the formation of a field with such heterogeneities the hydrophysical and meteorological conditions have to be investigated. The complexity of meteorological measurements indicated that the vessel was on the northern periphery of the Southern Subtropical Atmospheric Anticyclone. This zone can be characterised by small baroclinic pressure gradients with quite small changes in the wind velocity, the average number being $5.2 \mathrm{~m} \mathrm{~s}^{-1}$. A 3 to 4 d periodicity with an amplitude of about $3 \mathrm{~m} \mathrm{~s}^{-1}$ was monitored within the temporal changes of the components of the wind velocity. These periods are close to the local inertial period, which is equal to $4.1 \mathrm{~d}$. Less frequent periods (17 to $20 \mathrm{~d}$ ) have also been traced for this region and are associated with large-scale fluctuations of the centre of the Subtropical Atmospheric Anticyclone.

\section{Mesoscale structure and dynamics of the current field}

The vertical density structure had the following typical features. The upper mixed layer had a thickness from 20 to $25 \mathrm{~m}$ followed by a thermocline with a sharp density gradient. Two maxima of the Brunt-Väisälä frequency $N(z)$ were noted for the majority of stations. The first one was located at a depth of 20 to $25 \mathrm{~m}$ and typically had a $N(z)$ of 10 to $15 \times 10^{-3} \mathrm{rad} \mathrm{s}^{-1}$. The second one was recorded at a depth of 90 to $110 \mathrm{~m}$ with an $N(z)$ of up to $30 \times 10^{-3} \mathrm{rad} \mathrm{s}^{-1}$, which corresponded to an oscillation period of $3.5 \mathrm{~min}$ (Figs. 4 \& 5).

The mean velocities in the upper layer of the ocean were 30 to $40 \mathrm{~cm} \mathrm{~s}^{-1}$ and the current was directed from the northwest to the southeast, approximately along the South American continent. From CTD data this current has been identified as the southern limb of the North Passat Current, which is active within a region of the Interpassat Counter-Current formation. An analysis of records from the buoy stations revealed intensive fluctuations of currents with a period of $3.3 \mathrm{~d}$ in the upper $100 \mathrm{~m}$ layer, where velocities quickly diminished with depth. The phase shift between the components of the current velocity vector was close to $90^{\circ}$ for such fluctuations. Temperature fluctuations with the same period were registered at a depth of 150 to $200 \mathrm{~m}$. The typical frequency spectra of the current fluctuations (along the longitude, $V \mathrm{~m}$, and the latitude, $V p)$ and spectra of temperature fluctuations, $S_{T}(\omega)$, for the horizon $100 \mathrm{~m}$ are shown in Fig. 6. The distinct patterns in these spectra are that the maxima mainly developed at a period of $77.2 \mathrm{~h}$. This is $20 \%$ less than the local inertial period. Peaks corresponding to the period of the semi-diel tide are also visible.

Examples of the vertical profiling of the current, from the region of the buoy stations, are shown in Fig. 7. These data were averaged at $10 \mathrm{~m}$ intervals down the vertical profile to exclude the impact of the pitching vessel on the measurements. The layered pattern of the current velocity components, on the longitude $(\mathrm{Vm})$ and the latitude $(V p)$, from the surface to $200 \mathrm{~m}$ depth are obvious. The size of heterogeneities in the upper $100 \mathrm{~m}$ layer were 30 to $40 \mathrm{~m}$ and increased to $70-80 \mathrm{~m}$ with depth. Current profiles were consecutively measured (Fig. 7) over $82 \mathrm{~h}$, which is close to the period of current fluctuation at the buoy stations. This shows that the temporal periods in the fluctuations of current velocity in the buoy stations data and vertical profiling data are in a good agreement.

\section{Assessments of heterogeneities}

Current velocity fluctuations with a near-inertial period were noted in data from all 4 buoy stations Vertical profiling of current measurements shows a well-developed layered pattern. Such features are typical for internal waves with a period close to the inertial frequency (Webster 1968, Pollard 1970, Krause 1976 , Phillips 1980). The horizontal heterogeneities associ-

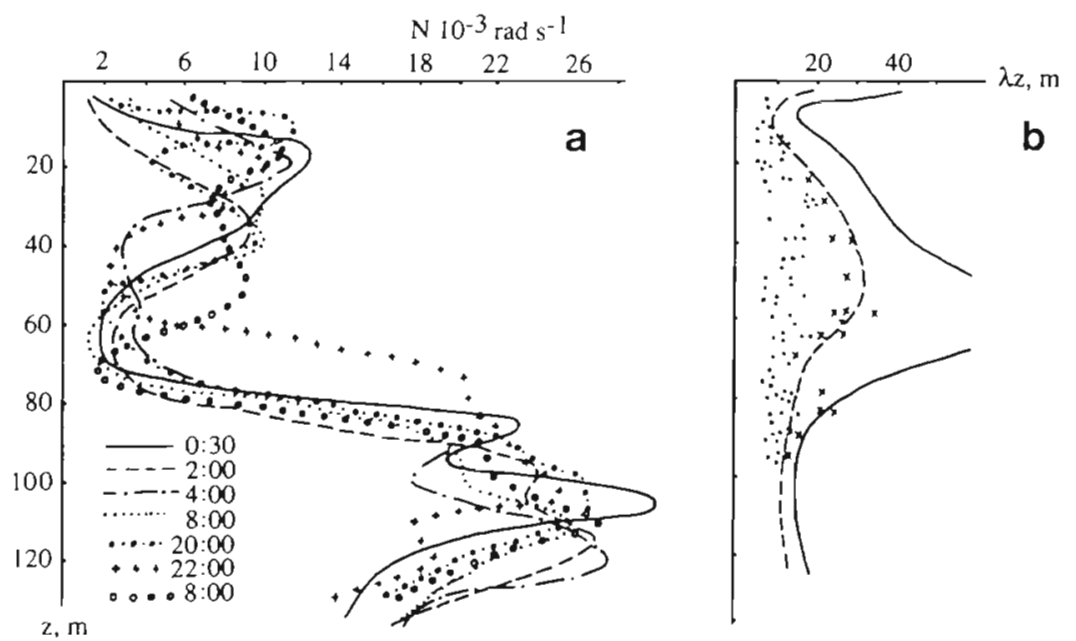

Fig. 4. (a) Vertical profiles of the BruntVäisălä frequency $(N)$ during a series of CTD casts and (b) characteristics of the vertical lengths of the near-inertial gravity wave calculated from these profiles for the long-term drift station, Stn 4921. Time of casts $-1.0: 30 \mathrm{~h}, 2: 2: 00 \mathrm{~h}, 3: 4: 00 \mathrm{~h}$, 4: $8: 00 \mathrm{~h}, 5: 20: 00 \mathrm{~h}, 6: 22: 00 \mathrm{~h}, 7: 8: 00 \mathrm{~h}$ (GMT). In (b). $\lambda_{z}$ : calculated maximal length (solid line) and minimal length (dashed line) of the vertical lengths of the near-inertial period waves; $\{x \mid$ distances between the layers with the maximal bioluminescence values (m); and $(\bullet)$ sizes of the minimal bioluminescence heterogeneities (m) 
Fig. 5. (a) Vertical profiles of the Brunt-Väisälä frequency $(N)$ during a series of CTD casts and (b) characteristics of the vertical lengths of the near-inertial gravity wave calculated from this profiles for the longterm drift station, Stn 4935. Time of casts - 1 10:44 h, 2:5:50 h, 3:3:50 h, $4: 9: 07 \mathrm{~h}(\mathrm{GMT}) . \ln (\mathrm{b}), \lambda_{\text {, }}$ the calculated maximal length (solid line) and minimal length (dashed line) of the vertical length of the near-inertial period waves; $(+)$ distances between the layers with the maximal bioluminescence values $(\mathrm{m})$; and $(\bullet)$ sizes of minimal bioluminescence heterogeneities (m)
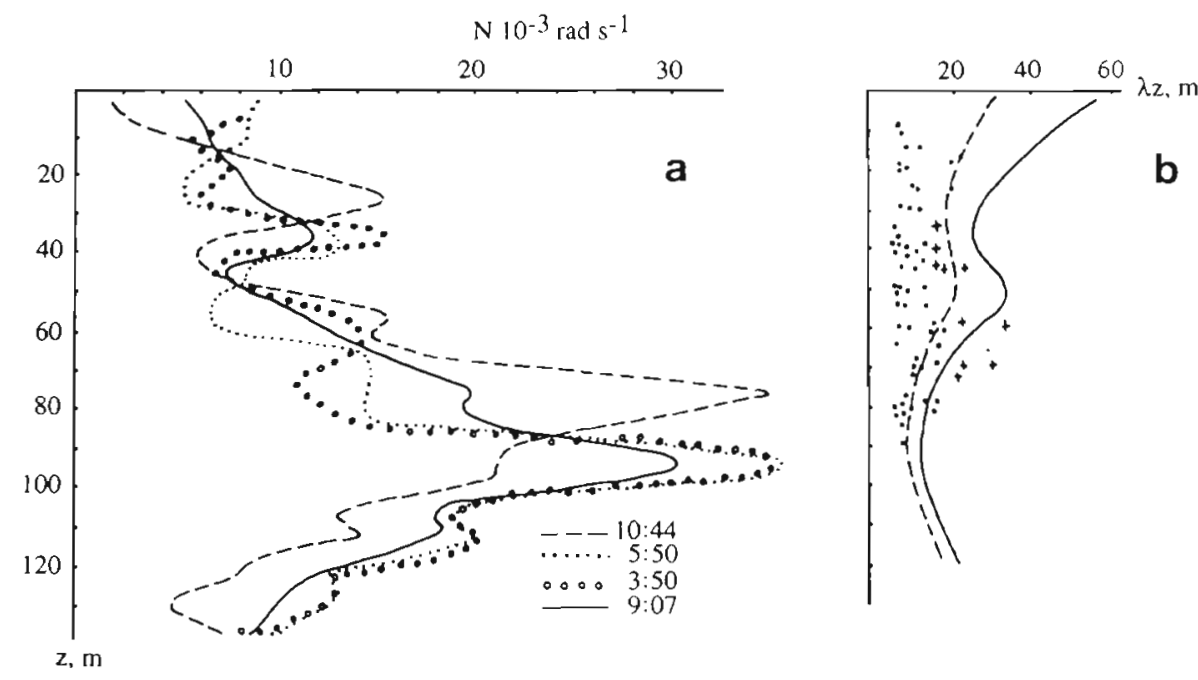

ated with these waves can be estimated and compared with heterogeneities in the bioluminescent field. The linear dispersion ratio can be used for:

$$
k_{z}=k\left[N^{2}(z)-\omega^{2}\right]^{05}\left[\omega^{2}-f^{2}\right]^{-0.5}
$$

where $k_{z}=2 \pi / \lambda_{z}$ and represents the vertical wave number, $k_{x}=2 \pi / \lambda_{x}$ and is the horizontal wave number, $N(z)$ is the Brunt-Väisälä frequency and $f$ is the Coriolis parameter. We studied the relationship $\lambda_{x}=f\left(\lambda_{z}, N\right)$ for the conditions of our field measurements (Fig. 8). The most typical Brunt-Väisälä frequency numbers for the upper 60 to $80 \mathrm{~m}$ layer are represented in the plot. The horizontal heterogeneities in the bioluminescence field were from 5 to $20 \mathrm{~km}$ and vertical heterogeneities were from 10 to $40 \mathrm{~m}$. There was good agreement with the direct measurements of the horizontal heterogeneities of the bioluminescence field (see Fig. 2) and its spectral estimates (see Fig. 3).

Profiling of the vertical bioluminescence revealed heterogeneities of 40 to $50 \mathrm{~m}$ in size (see Fig. 2b). The small vertical heterogeneities $(10 \mathrm{~m})$ corresponded to the horizontal heterogeneities of 2 to $6 \mathrm{~m}$ in size (Fig. 8). Vertical heterogeneities $10 \mathrm{~m}$ in size were not detected in profiles of the current shown in Fig. 7 as heterogeneities of this size were previously filtered out to exclude the impact of the pitching of the vessel. However, such heterogeneities were found in many spectra of vertical wave numbers from data obtained using acoustic current profilers in the region (Bulgakov et al. 1992). Vertical heterogeneity of currents with such sizes are known in the vertical structure of the current field from other regions (Evans et al. 1979). Hence, the horizontal and vertical heterogeneities of the bioluminescence field appeared to be in good agreement with estimates obtained from the dispersion ratio Eq. (6). This shows that the horizontal and vertical structure of the bioluminescence field is related to the studied field of internal waves of nearinertial frequency. To analyse the vertical structure of the bioluminescence field in detail the results of a
Fig. 6. Spectra of the current velocity and temperature fluctuations calculated from data from buoy stations. $S_{V m}$ : spectra of longitude current velocity, $S_{V_{p}}$ : spectra of latitude current velocity (horizon $25 \mathrm{~m}$ ), $S_{T}$ : spectra of temperature fluctuations (horizon $100 \mathrm{~m}$ ); cps: frequency of fluctuations (cycles $\mathrm{s}^{-1}$ ): T: period of fluctuations (h)
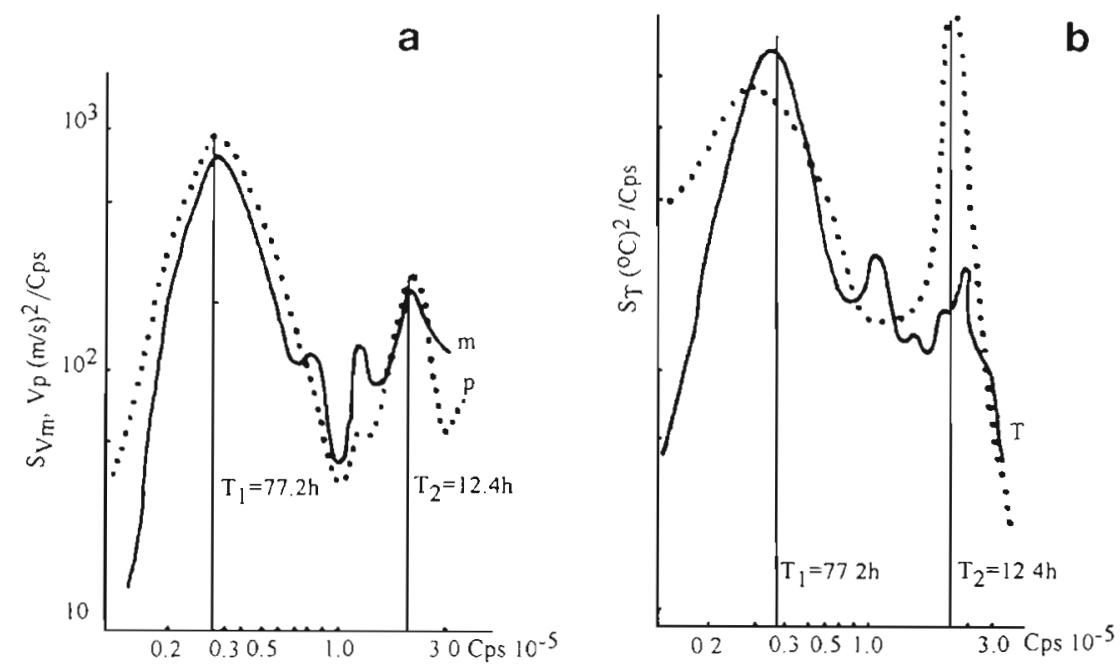
a $\quad \mathrm{mm} \mathrm{ms}^{\cdot 1}$

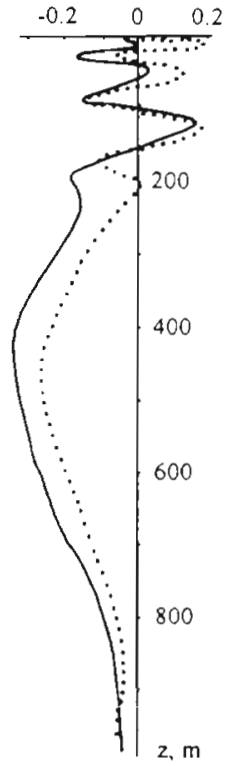

b $v_{p} \mathrm{~ms}^{-1}$

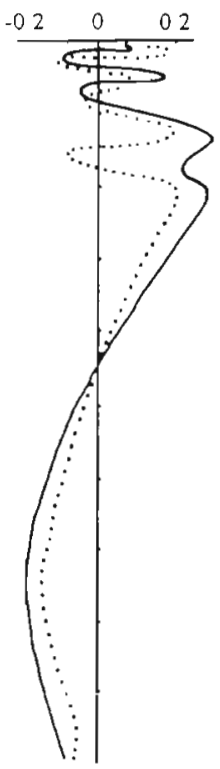

Fig. 7 Typical vertical profiles of the Iongitude $(\mathrm{Vm})$ and latitude $(V p)$ current velocity. Solid and dotted lines: components of the current velocity vectors measured over $82 \mathrm{~h}$

sequence of casts conducted at Stns 4921 and 4935 were used (Fig. 2b). They were accompanied by a series of CTD casts used to estimate patterns of the Brunt-Väisälä trequency (Figs. 4 \& 5). Obviously the $N(z)$ numbers are quite variable. This is evident from variations in values in the upper maximum and the depth of their location, thus, the depth changes from 10 to $50 \mathrm{~m}$ within $5 \mathrm{~h}$ of measurements at Stn 4921 and from 25 to $40 \mathrm{~m}$ at Stn 4935 within the same period

From Eq. (6), the vertical profiles of $N(z)$ and the data on the horizontal bioluminescence sizes, the minimal numbers of $\lambda_{z}$ (dashed lines) and their maximal values (solid lines) are defined. The distances between single

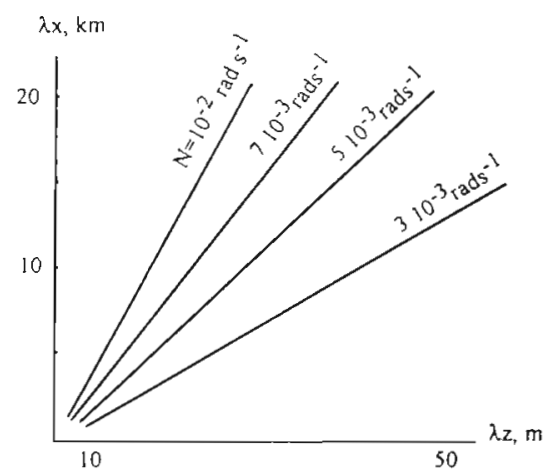

Fig. 8. Calculated relationships between the horizontal $\left(\lambda_{x}\right)$ and vertical $\left(\lambda_{2}\right)$ lengths of the near-inertial waves for conditions of the western Tropical Atlantic. Brunt-Väisälä frequency numbers $(N)$ are indicated above each of the curves heterogeneities $\left(B_{p}\right)$ are indicated by dots and crosses and show the distances between layers of the bioluminescence maxima. The distance between single flashes $\left(8\right.$ to $10 \mathrm{~m}$ ) corresponds well to minimal size $\lambda_{z}$ for layers with enhanced $N(z)$, but differs for the intermediate depths. The thickness of layers between 2 maxima (crosses) practically mirror the calculated patterns of $\lambda_{z}(z)$ vertical profiles. This means that horizontal and vertical estimates of the bioluminescence field heterogeneities correspond to the local estimates obtained for the near-inertial gravity waves.

\section{Global scale trends}

To reveal more general trends, data on the typical dimensions of bioluminescence heterogeneities from other regions of the Atlantic Ocean were analysed. From these analyses it is quite evident that the average size of heterogeneities and the variance of the average size are a function of latitude (Fig. 9). The size and its variance decrease towards the equator. Data for this figure were averaged latitudinally, over $5^{\circ}$ intervals, and the estimated values of bioluminescence (including measurements from the previous cruises to the tropical zone) were placed in the middle of each interval. A box-and-whisker plot was used to represent the results. The bottom and the top of the box point out the first and the third quartiles respectively. The whiskers (the vertical lines from the box) extend to the lowest and highest values of the parameter. The measurements which have a high deviation are represented separately by symbols. The horizontal line within a box shows the median. The fact that the variance of the bioluminescence wavelengths diminishes from the equator toward the north can be interpreted as follows. It is known that the near-internal waves of a given type are induced in the upper layer of the ocean by the

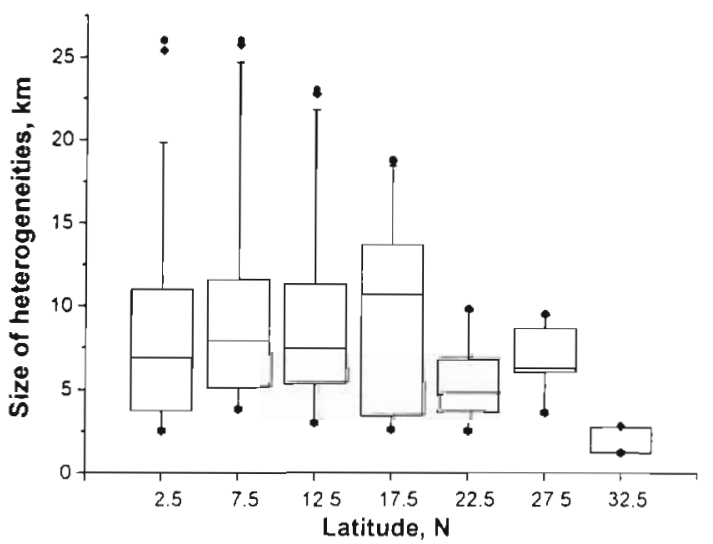

Fig. 9. Relationship between the horizontal size of bioluminescence heterogeneities and the latitude of measurements 
pressure in the tangential wind, with a period which is close to inertial ones (Pollard 1970, Krause 1976. D'Asaro 1985). From the linear dispersion ratio Eq. (6) it is deducible that shifts in the fluctuations in frequency determine the horizontal wavelength:

$$
\lambda_{x}=\lambda_{z} N(z)\left(\omega^{2}-f^{2}\right)^{-0.5}
$$

Taking into account the viscosity in the upper layer of the ocean (Krause 1976), $\lambda_{x} / \lambda_{z}=O\left(E^{0.5}\right)$, where $E$ (the Ekman number) $=v\left(f D^{2}\right)^{-1}$ and $v$ is the coefficient of the turbulent viscosity.

It is possible to show that the displacement $(\varepsilon)$ of frequency of near-inertial internal waves concerned with the inertial frequency peaks $(f)$ is as follows:

$$
\varepsilon=0.5 N(z) f^{-1} \lambda_{x}{ }^{-1}(v / f)^{0.5}
$$

and hence the horizontal length of such internal waves depends on latitude $(\varphi)$ as follows (Vasilenko \& Golenko 1977):

$$
\lambda_{x}=0.25(\Omega \varepsilon \sin \varphi)^{-1} N(z)\left(0.5 \mathrm{v} /(\Omega \sin \varphi)^{0.5}\right.
$$

where $\Omega$ is the angular speed of the Earth rotation.

At relative stability of $N(z), \varepsilon$, and $v$, the effect of a reduction of the horizontal near-inertial wavelength should be observed with an increase in the latitude. This corresponds with the measurements shown in Fig. 9 .

This effect can also be explained by the following. At $\omega=t=2 \Omega \sin \varphi$, the horizontal component of the phase speed of the internal waves becomes equal to zero, that is, equivalent to the effect of a wall. Therefore, the internal waves with frequencies $\omega=f$ are reflected in regions of low latitudes. Small-scale internal waves with frequencies $\omega>f$ can be distributed in various directions and hence, in regions of low latitudes, internal waves of various periods and lengths can exist. Low-frequency (large-scale) waves are filtered out; therefore, with an increase of latitude the horizontal sizes of waves and their dispersion should decrease. Such an effect is observed with the horizontal bioluminescence scales shown in Fig. 9.

The impact of internal waves on the distribution of planktonic organisms generating the bioluminescence field of the ocean were monitored on a finer spatialtemporal scale. Haury et al. (1983) showed that phytoand zooplankton organisms were redistributed by tidally generated high-frequency internal wave packets propagated with a period of about 10 min. Organisms are unable to resist internal waves with a velocity of about 18 to $38 \mathrm{~cm} \mathrm{~s}^{-1}$ and can be considered as passive particles. The spatial-temporal relationship between bioluminescence intensity and physical parameters has been reported for other regions of the Atlantic Ocean. Bitukov et al. (1988) conducted simultaneous measurements of bioluminescence intensity and temperature in the upper $100 \mathrm{~m}$ layer in the North Passat Current. They found high correlation values between the fluctuation in depth of the location of maximal bioluminescence intensity and that of the $22^{\circ} \mathrm{C}$ isotherm. This correlation was highest at the thermocline, within the range of 40 to $60 \mathrm{~m}$ depth, where the internal waves were usually well developed.

\section{Planktonic fractions of the bioluminescence field and internal waves}

The consequences of the dynamics of internal waves within the thermocline were also reflected in the spatial heterogeneity of zooplankters inhabiting the upper layers of the western tropical Atlantic Ocean. This was observed in data collected from pump measurements of mesozooplankton biomass within the upper layer $(0$ to $6 \mathrm{~m}$ ) and temperature measurements within the thermocline (towed submersible gear) conducted from a vessel which was underway (Rudyakov \& Tsejtlin 1989). The power spectra of the temperature and zooplankton biomass exhibited coherent local peaks of spectral density at similar wavelengths, in a range from 250 to $20 \mathrm{~km}$. The similarity of the statistical structure of the temperature and zooplankton fields was also reflected in the relatively high correlation between the averaged spectra slopes of both parameters. Possibly, the impact of the internal gravity waves might be different with respect to the different components of the planktonic communities (their phyto- and zooplankton fractions, which contribute to the bioluminescence signal). The response of the zooplanktonic fraction to wave propagation is more mechanical and leads to redistribution of the organisms in space. The response of the phytoplanktonic fraction combines mechanical and physiological events. In tropical waters the propagation of waves causes the injection of nutrients into the upper layers, which together with changes of light intensity enhances the primary production (Holloway 1984, Lande \& Yentsch 1988).

Further work is required on the contribution of the phyto- and zooplankton fractions to the formation of the bioluminescence intensity of the tropical Atlantic Ocean regions. The similarity of the macroscale trends of zooplankton biomass and changes in bioluminescence intensity were noted in the transect, from the enriched Benguela waters to the oligotrophic waters of the macroscale anticyclonic gyre of the South Atlantic Ocean (Evstigneev \& Bitukov 1990, Evstigneev et al. 1994j. However, in the oligotrophic waters of the eastern Atlantic Ocean, as in the Sargasso Sea, it is zooplankton (crustaceans, larvaceans, etc.) which constitutes the major part of the stimulated bioluminescence in the upper layers (Swift et al. 1983, 1985). Strong cor- 
relation between mesoplankton biomass and bioluminescence was noted for other tropical regions, for instance in Hawailan waters (Rudyakov \& Tsejtlin 1989). The governing role of zooplankton in the formation of the bioluminescence field has been noted for other regions as well (Lapota \& Losee 1984). However, in the case of the western Tropical Atlantic, phytoplanktonic algae of the genera Glenodinium, Peridinium and Exuviaella were the dominant components of the stimulated bioluminescence (Evstigneev et al. 1990). These should be treated as preliminary results, as no direct assessments of the contribution of different plankton fractions to the bioluminescence intensity were made.

\section{CONCLUSIONS}

Comparisons of the averaged horizontal and vertical dimensions of the heterogeneities of the bioluminescence field with those of the near-inertial gravity waves indicated good agreement in the upper $100 \mathrm{~m}$ layer. The waves behave as quasi-stationary fluctuations, generating the conditions for aggregation of the bioluminescent organisms along the vertical and the horizontal planes.

More precise assessments of the mechanisms governing the formation of the bioluminescence field in the ocean need to be made. The contribution of other factors acting together with the near-inertial gravity waves has to be estimated. The mechanism of aggregation, of how the bioluminescent organisms aggregate into patches and layers, is still poorly known. Possibly the sequences of convergence and divergence zones within internal waves play a major role in these events. The divergence zone, at least, causes the formation of slicks and water ripples on the water surface on a scale of hundreds of metres. In the case of inertial gravity waves, similar well-defined effects have yet to be evaluated.

Acknowledgements. The authors are grateful to Dr A. V Prusov, V. L. Vladimirov, and Yu. N. Golybev for the technical assistance with the statistical treatment of the data and for useful comments. We also thank Y. Kuklina and E. G. Nechesin for the meteorological data. This work was partially supported by a grant from ONR N00014-95-1-0089, for which we are grateful.

\section{LITERATURE CITED}

Angel MV, Fasham JR (1983) Eddies and biological processes In: Robinson AR (ed) Eddies in marine science. SpringerVerlag, New York, p 492-524

Bitukov EP (1982) Seasonal variability and the spatial heterogeneity of the bioluminescence in the Mediterranean Sea.
Ekol Mor 8:10-20 (in Russian)

Bitukov EP, Olshanski YuI, Serikova IM (1988) The fine-scale structure of the bioluminescence field and their relationship with the distribution of the hydrological characteristics. Okeanologiya 28:752 (in Russian)

Bradford JM, Heath RA, Chang FH, Hay CH (1982) The effect of warm-core eddies on oceanic productivity of northern New Zealand. Deep Sea Res 29:1501-1516

Bulgakov NP, Dochenko SF, Kushnir VM, Loshakin PF, Mankovski BI (1991) Hydrological studies of the Carribean Sea. Naukova Dumka, Kiev (in Russian)

Bulgakov NP, Kushnir VM, Repetin LN (1992) The north equatorial countercurrent in the West Atlantic during the summer of 1988. Phys Oceanogr 4(2):151-156

Buskey E (1993) A bioluminescence budget for the northern Arabian Sea during March 1993. In: Abstracts, Bioluminescence Symposium. Westin Maui, Kaanapali Beach, Hawaii. November 5-10,1993, p 70

D'Asaro EA (1985) The energy flux from the wind to nearinertial motions in the surname mixed layer. $J$ Phys Oceanogr 15(8):1043-1059

Evans DL, Rossby HT, Mork M, Gytre T (1979) YVETTE-a free fall shear protiler. Deep Sea Res 26(6A):703-718

Evstigneev PV, Bitukov EP (1990) Bioluminescence of marine copepods (Bioluminescenciya morskih copepod). Naukova Dumka, Kiev (in Russian)

Evstigneev PV, Voronova OK, Scherbatenko PV, Bocharova RK (1990) A study of bioluminescence of the superficial layers of the tropical Atlantic Ocean. Ekol Mor 34:15-21 (in Russian)

Evstigneev PV, Williams R, Piontkovski SA, Bileva OK (1994) Spatial temporal succession and distribution of bioluminescent organisms of the central Atlantic Ocean. In: Campbell AK, Kricka LJ, Stanley PE (eds) Bioluminescence and chemiluminescence. John Wiley \& Sons, Chichester, p 123-127

Falkowski PG, Ziemann D, Kolber Z, Bienfang PK (1991) Role of eddy pumping in enhancing primary production in the ocean. Nature 352:55-57

Gitelson II, Filimonov VS (1980) The studies of the bioluminescent potential for the assessment of the biological structure of waters. Trudy Inst Okeanol Akad Nauk SSSR 90:244-251 (in Russian)

Gitelson II, Levin LA, Utushev RN, Cherepanov OA, Chygynov YuV (1992) The bioluminescence in the ocean. Hydrometeoizdat, St. Petersburg (in Russian)

Haury LR, Wiebe PH, Orr MH, Briscoe MG (1983) Tidally generated high-frequency internal wave packets and their effects on plankton in Massachusetts Bay. J Mar Res 41(1):65-112

Herring PJ (1993) Depth distribution of bioluminescent crustaceans in the eastern north Atlantic. In: Abstracts, Bioluminescence Symposium. Westin Maui, Kaanapali Beach, Hawai. November 5-10, 1993, p 51

Holloway G (1984) Effects of velocity fluctuations on vertical distributions of phytoplankton. J Mar Res 42:559-571

Krause $E$ (1976) The interaction of the atmosphere and the ocean (Vzaimodeistvie atmosferyi i okeana). Hydrometeoizdat, Leningrad (in Russian)

Lande R, Yentsch CS (1988) Internal waves, primary production and the compensation depth of marine phytoplankton. J Mar Res 10(3):565-571

Lapota D. Losee JR (1984) Observations of bioluminescence in marine plankton from the Sea of Cortez. J Exp Mar Biol Ecol 77(3):209-240

Lapota D, Paden S, Duckworth D, Rosenberg DE, Case JF (1994) Coastal and oceanic bioluminescence trends in the 
Southern California Bight using MOOREX bathyphotometers. In: Campbell AK, Kricka LJ, Stanley PE (eds) Bioluminescence and chemiluminescence. John Wiley \& Sons, Chichester, p 127-131

Mankovsky VI (1996) The base of the Ocean optics. MHIpubl, Sevastopol (in Russian)

Mann KH, Lazier JRN (1991) Dynamics of marine ecosystems: biological-physical interactions in the oceans. Blackwell Scientific Publ, Oxford

Marra J (1989) Marine bioluminescence and upper ocean physics: seasonal changes in the Northeast Atlantic. Oceanography 2(1):36-38

Marra J. Hartwig EO (1984) Biowatt: a study of bioluminescence and optical variability in the sea. EOS Trans Am Geophys Union 65:732-733

Owen RW (1981) Fronts and eddies in the sea: mechanism, interactions and biological effects. In: Longhurst ARL (ed) Analysis of marine ecosystems. Academic Press, New York, p 197-233

Phillips OM (1980) The dynamics of the upper layer of the ocean. Hydrometeoizdat, Leningrad

Piontkovski SA, Goldberg GA (1984) The ratio of spatial to temporal variability of planktonic fields. Ekologiya Mosc $1: 42-46$ (in Russian)

Ptontkovski SA, Williams R (1995) Multiscale variability of tropical ocean zooplankton biomass. ICES J Mar Sci 52: $643-656$

Piontkovski SA, Williams R, Peterson W, Kosnirev VK (1995) Relationship between oceanic mesozooplankton and energy of eddy fields. Mar Ecol Prog Ser 128:35-41

Pionkovski SA, Williams R, Peterson WT, Yunev OA, Minkina NI, Vladimirov VL, Blinkov A (1997) Spatial heterogeneity of the planktonic fields in the upper mixed layer of the

Editorial responsibility: Otto Kinne (Editor),

Oldendorf/Luhe, Germany open ocean. Mar Ecol Prog Ser 148:145-154

Pollard R (1970) On the generation by wind of internal waves in the ocean. Deep Sea Res 17:795-812

Rudyakov YuA, Tsejtlin VB (1989) Mesoplankton biomass and bioluminescence in bathypelagic oceanic zone. Oceanology 29(5):819-824 (in Russian)

Shifrin KS (1978) Optic of the ocean. In: Ocean Physics, Vol 1 Nauka, Moscow, p 340-396 (in Russian)

Swift E, Biggley WH, Verity PG, Brown DT (1983) Zooplank ton are major sources of epipelagic bioluminescence in the southern Sargasso Sea. Bull Mar Sci 33(4):855-863

Swift E, Lessard EJ, Biggley WH (1985) Organisms associated with stimulated epipelagic bioluminescence in the Sargasso Sea and the Gulf Stream. J Plankton Res 7:831-848

Urdenko VA (1977) Measurement of the bioluminescence field in the ocean by means of a moving linear sensor. Oceanology 17(4):480-483

Vasilenko VM, Golenko NN (1977) On some features of mesoscale motions in the ocean. Oceanology 17(4):383-386 (in Russian)

Vinogradov ME, Gitelson II, Sorokin YuI (1971) Toward the spatial structure of the communities of the euphotic zone of the tropical ocean waters. Nauka, Moscow (in Russian)

Vladimirov VL, Urdenko VL, Neyimin GG, Paramonov AI Zemlyanaya LA (1972) Studies of the bioluminescent field Mar Hydrophysical Res 2:187-196 (in Russian)

Webster F (1968) Observations of inertial-period motion in the deep sea. Rev Geophys 6:470-490

Wiebe PH, Hulburt EM, Carpenter EJ, Jahn AE, Knapp GP Boyd SH, Ortner PB, Cox JL (1976) Gulf Stream cold core rings: large-scale interaction sites for open ocean plankton communities. Deep Sea Res 23:685-710

Submitted: December 3, 1996; Accepted: September 9, 1997 Proofs received from author(s): December 5, 1997 